\title{
Pemeriksaan Gratis dan Pendidikan Kesehatan Tentang Efektivitas Kacang Hijau dan Kacang Kedelai dalam Meningkatkan Kadar Hemoglobin dalam Darah
}

\author{
Iis Sopiah Suryani \\ Universitas Bhakti Kencana Tasikmalaya, Jl. R.E. Martadinata No.142, Cipedes, Kec. Cipedes, \\ Tasikmalaya, Jawa Barat 46133 \\ Email: iissopiahsuryani@gmail.com
}

\begin{abstract}
ABSTRAK
Pada era 4.0 terjadi persaingan yang ketat diberbagai aspek, diperlukan sumber daya manusia yang berkualitas. Dalam menghasilkan SDM yang berkualitas dapat terhambat karena kesehatan dan status gizi. Angka Kejadian anemia masih tinggi.Terutama pada wanita remaja, remaja rentanmengalami anemia karena sedang dalammasa transisi dan juga karena menstruasi. Anemia dapat disebabkan oleh beberapa faktordiantara nya kurang nya asupan gizi, selain itu pola menstruasi, pengetahuantentang anemia, anemia kekurangan zat besi bisa dipenuhi dengan mengkonsumsi zat fe, akan tetapimengkonsumsi suplemen yang mengandung zat besi dalam jumlah banyak dapatmerusak lapisan usus. Berdasarkan hasil penelitian yang telah dilakukan oleh penulis bahwa kacang hijau dan kacang kedelai dapat meningkatkan kadar hemoglobin dan saturasi oksigen dalam darah, maka tujuan pengabdian masyarakat ini untuk meningkatkan pengetahuan remaja tentang anemia. Metode pelaksanaan adalah dengan melakukan pemeriksaan gratis tekanan darah, pemeriksaan HB dan pemeriksaan saturasi oksigen, kemudian memlakukan pendidikan kesehatan sesuai hasilpenelitian yang telah dilakukan. Hasil kegiatan pengabdian masyarakat pre test pengetahuan remaja $60.98 \%$ dalam kategori baik, $34.15 \%$ kategori cukup, $4.87 \%$ kategori kurang, post test $82.93 \%$ kategori baik, $17.07 \%$ kategori cukup. Terdapat perubahan pengatahuan remaja sebelum dan sesudah pendidikan kesehatan. Pengetahuan remaja setelah dilakukan pengabdian masyarakat menjadi lebih tahu tentang efektivitas kacang hijau dan kacang kedelai. Yang lebih efektif dalam meningkatkan kadar hemoglobin dan saturasi oksigen adalah kacang hijau.
\end{abstract}

Kata Kunci: Pendidikan kesehatan; Kacang hijau; Remaja

\section{ABSTRACT}

In the era of 4.0, there was intense competition in various aspects, it required quality human resources. In producing quality human resources, it can be hampered by health and nutritional status. The incidence of anemia is still high. Especially in adolescent women, adolescents are prone to experiencing anemia because they are in a transitional period and menstruation. Anemia can be caused by several factors, including lack of nutritional intake, besides menstrual patterns, knowledge of anemia, iron deficiency anemia can be met by consuming iron, but taking supplements that contain large amounts of iron can damage the intestinal lining. Based on the results of research conducted by the author that green beans and soybeans can increase hemoglobin levels and oxygen saturation in the blood, this community service aims to increase adolescent knowledge about anemia. The research method is to do a free blood pressure check, HB examination, and oxygen saturation check, then apply health education according to the research results. The results of community service activities pretest adolescent knowledge $60.98 \%$ in the excellent category, $34.15 \%$ in enough category, $4.87 \%$ in the low category, $82.93 \%$ in the outstanding category, $17.07 \%$ in the excellent category. There were changes in adolescent knowledge before and after health education. Community service becomes more aware of the effectiveness of green beans and soybeans. Mung beans are more effective at increasing hemoglobin levels and oxygen saturation.

Keywords: Health Education; Green Beans; a Teenager 


\section{PENDAHULUAN}

Pada era 4.0 sekarang ini terjadi persaingan yang ketat diberbagai aspek, oleh karena itu diperlukan sumber daya manusia berkualitas. Kesehatan dan gizi merupakan faktor yang paling kuat dalam mempengaruhi sumber daya manusia. Usia remaja merupakan perubahan dari masa anak-anak ke dewasa yang mengalami banyak perubahan dari berbagai aspek. Sehingga membutuhkan lebih banyak gizi, membutuhkan asupan gizi yang optimal untuk masa pertumbuhan dan perkembangan nya. Di Indonesia masyarakat. Menurut WHO prevalansi anemia didunia berkisar $40-88 \%$ jumlah penduduk remaja 26,2\% (Bappenas, 2013). Sementara menurut Simanungkalit (2019) sebanyak 63,4\% remaja putri di Indonesia mengalami anemia.

Anemia dikarenakan oleh beberapa faktor diantara nya kurang asupan gizi nutrisi, menstruasi, pengetahuan tentang anemia, tentang status gizi juga mempengaruhi. Jumlah zat besi yang dikeluarkan tubuh sekitar1, $0 \mathrm{mg} / \mathrm{hari}$ untuk wanita ditambah $0,5 \mathrm{mg}$ pada saat menstruasi. Zat besi yang diserap hanya $10 \%$ konsumsi yang di haruskan oleh wanita $15 \mathrm{mg}$. Kebutuhan zat besi dapat diperoleh dengan mengkonsumsi tablet fe, tetapi zat besi dalam suplemen jika dikonsumsi dalam jumlah besar dapat memberikan beberapa efek samping misalnya kerusakan pada lapisan usus, syok dan kegagalan hati (Arismas, 2011; Depkes RI, 2013; Fatimah, 2011; Yanuarti, 2014).

Cara lain untuk memenuhi kebutuhan zat besi yaitu dengan cara mengkonsumsi makanan yang banyak mengandung zat besi misalnya kacang hijau dan kacang kedelai. Kacang hijau dan kacang kedelai dapat diolah menjadi olahan makanan ringan dan lain nya. Kacang hijau bisa diolah menjadi bubur kacang hijau, dan kacang kedelai diolah menjadi sari kacang kedelai. Berdasarkan hasil penelitian yang telah dilakukan (Suryani, 2019; Astawan, 2009).

Kegiatan pengabdian ini bertujuan untuk memberikan pemeriksaan gratis dan pendidikan kesehatan tentang efektivitas kacang hijau dan kacang kedelai dalam meningkatkan kadar hemoglobin dalam darah kepada remaja. Kegiatan pengabdian masyarakat ini dilakukan di SMK Bhakti Kencana Tasikmalaya sekaligus sebagai Mitra pada pengabdian masyarakat ini dengan sasaran remaja yang merupakan siswi SMK Bhakti Kencana Tasikmalaya. 


\section{METODE}

Metode yang digunakan dalam kegiatan pengabdian masyarakat ini adalah dengan memberikan pendidikan kesehatan pada remaja yang merupakan siswi SMK Bhakti Kencana Tasikmalaya. Tentang efektivitas kacang hijau dan kacang kedelai dalam meningkatkan kadar hemoglobin dalam darah dan saturasi oksigen. Pendidikan kesehatan dilakukan untuk meningkatkan pengetahuan remaja tentang efektivitas kacang hijau dan kacang kedelai terhadap kenaikan hemoglobin dalam darah dan saturasi oksigen. Sebelum dilakukan pendidikan kesehatan siswi diberi kuesioner untukdi isi dan kemudian setelah diberi pendidikan kesehatan diberi kembali kuesioner agar tahu hasil evaluasi dari pendidikan kesehatan yang dilakukan. Alat yang digunakan untuk pemeriksaan yaitu spygmanometer, stetoskop, hb digital, dan saturasi oksigen yang diperoleh pada penelitian yang dilakukan berdasarkn hibah dari Dikti untuk Dosen Pemula. Pendidikan kesehatan dilakukan pada tanggal 16-17 Juli 2020 dengan jumlah siswi SMK 52 orang. Pendidikan kesehatan dilakukan di ruangan Gor SMK Bhakti Kencana Tasikmalayasebelum intervensi dan sesudah intervensi siswi diberikan kuesioner tentang materi penkes. Sehingga terukur pengetahuan sebelum dan sesudah intervensi. Pemeriksaan gratis dilakukan setelah kegiatan pendidikan kesehatan dilakukan bersama dengan tim dosen yang melakukan pengabdian masyarakat.

\section{HASIL, PEMBAHASAN, DAN DAMPAK}

Pengabdian masyarakat yang dilakukan berdasarkan hasil penelitian yang dilakukan bertujuan untuk meningkatkan pengetahuan remaja tentang pencegahan anemia yaitu salah satunya dengan mengkonsumsi makanan, berupa kacang hijau dan kacang kedelai. Dampak setelah dilakukan penngabdian masyarakat berupa intervensi pendidikan kesehatan pada remaja tentang efektivitas kacang hijau dan kacang kedelai dalam meningkatkan kadar hemoglobin dan saturasi oksigen dalam darah pada remaja yaitu meningkatnyadan bertambahnya pengethuan remaja tentang pencegahan anemia. Pada tabel 1, dapat dilihat pengetahuan remaja sebelum dan setelah diberikan intervensi berupa pendidikan kesehatan tentang efiktivitas kacang hijau dan kacang kedelai dalam meningkatkan kadar hemoglobin dan saturasi oksigen dalam darah. 
Tabel 1. Pengetahuan Remaja sebelum dan sesudah dilakukan pengabdian masyarakat

\begin{tabular}{ccccc}
\hline Pengetahuan & \multicolumn{2}{c}{ Pretest } & \multicolumn{2}{c}{ Posttest } \\
\cline { 2 - 5 } & $\mathrm{N}$ & $\%$ & $\mathrm{~N}$ & $\%$ \\
\hline Baik & 25 & 60,98 & 34 & 82,93 \\
\hline Cukup & 14 & 34,15 & 7 & 17,07 \\
\hline Kurang & 2 & 4,87 & 0 & 0 \\
\hline
\end{tabular}

Dari tabel 1 dapat dilihat pengetahuan remaja pada awal nya yaitu sebelum dilakukan intervensi tentang pendidikan kesehatan tentang efektivitas kacang hijau dan kacang kedelai dalam meningkatkan kadar hemoglobin dan saturasi oksigen dalam darah pengetahuan sebelum intervensi dalam kategori baik sebanyak 60.98\%, kategori cukup 34.15\% kategori kurang $4.87 \%$, setelah intervensi dilakukan pengetahuan dalam kategori baik $82.93 \%$ kategori cukup $17.07 \%$.berarti terdapat perubahan pengetahuan remaja sebelumdan setelah intervensi pendidikan kesehatan tentang efektivitas kacang hijau dan kacang kedelai dalam meningkatkan kadar hemoglobin dan saturasi oksigen.

Dokumentasi pada saat dilakukan pendidikan kesehatan pada remaja.

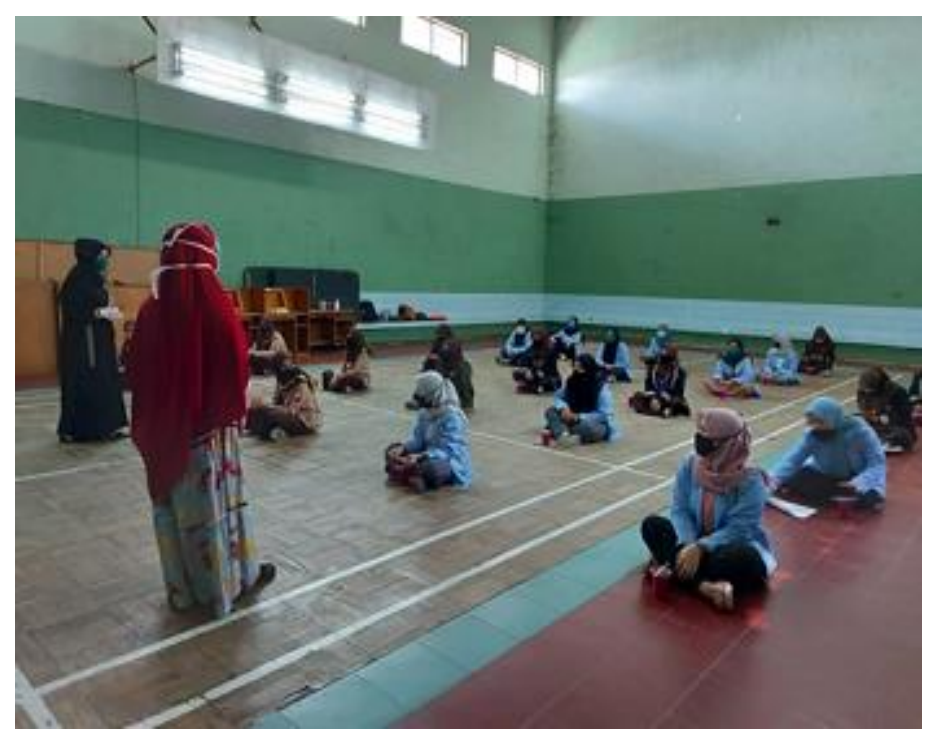

Gambar 1. Kegiatan Pendidikan Kesehatan pada Peserta

Pada gambar 1, merupakan dokumentasi kegiatan pendidikan kesehatan pada peserta tentang efektivitas kacang hijau dan kacang kedelai dalam meningkatkan hemoglobin dan saturasioksigen dalam darah pada remaja. 


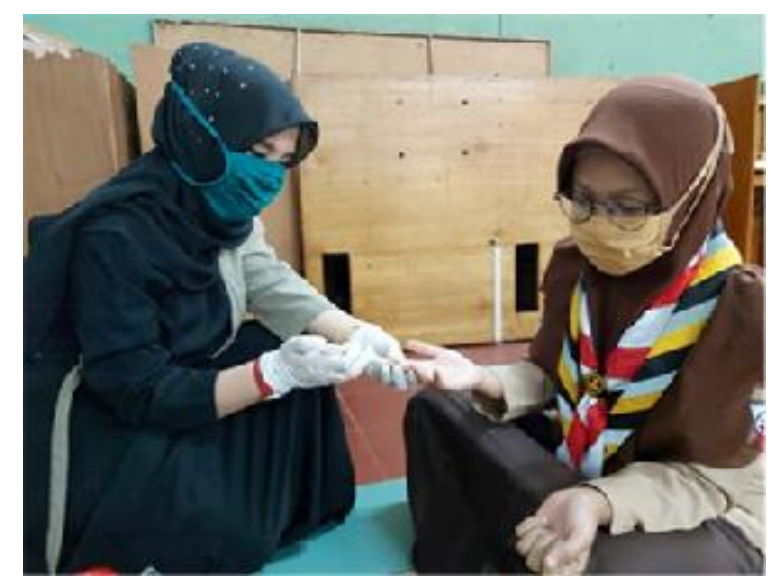

Gambar2. Pemeriksaan Hemoglobin dalam darah yang dilakukan setelah tindakan pendidikan kesehatan

Pada gambar 2, merupakan dokumentasi pada saat dilakukan Pemeriksaan Hemoglobin dalam darah siswa, kegiatan ini dilakukan setelah tindakan pendidikan kesehatan.

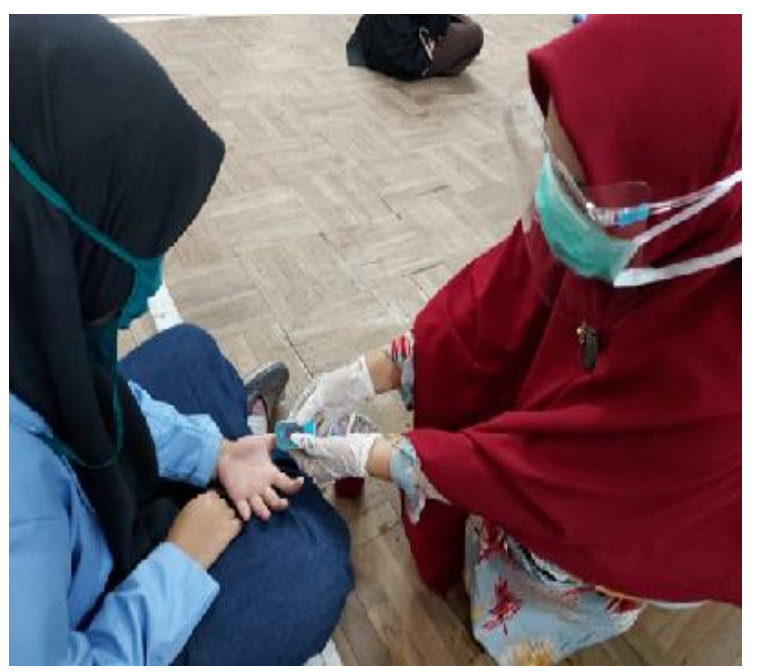

Gambar 3. Pemeriksaan saturasi oksigen pada remaja dilakukan setelah pemberian pendidikan kesehatan.

Pada gambar 3 merupakan dokumentasi pada saat Pemeriksaan saturasi oksigen pada remaja dilakukan setelah pemberian pendidikan kesehatan. Sedangkan pada gambar 4 dan 5 merupakan dokumentasi pada saat tim pengabdi sedang memberikan terkait pendidikan kesehatan kepada peserta. 


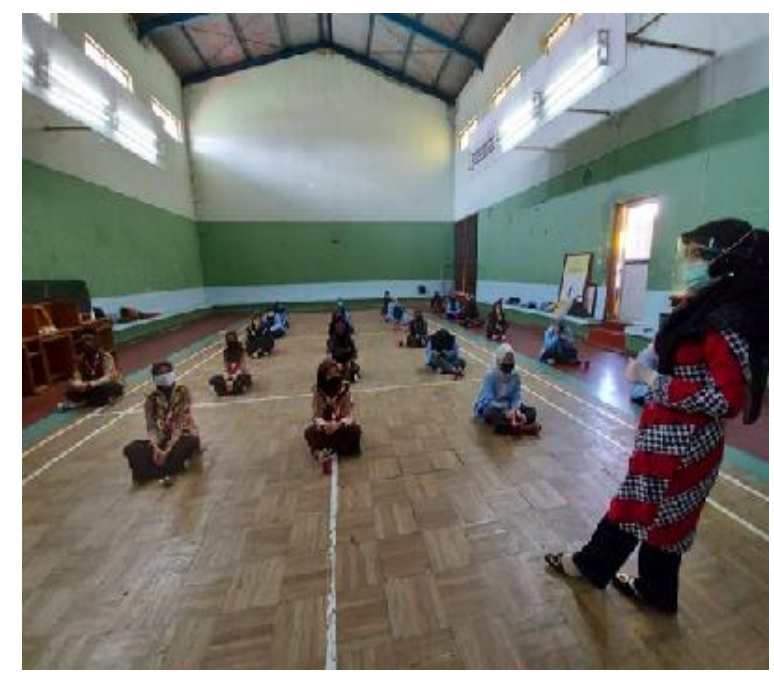

Gambar 4.Gambar pendidikan kesehatan oleh Tim

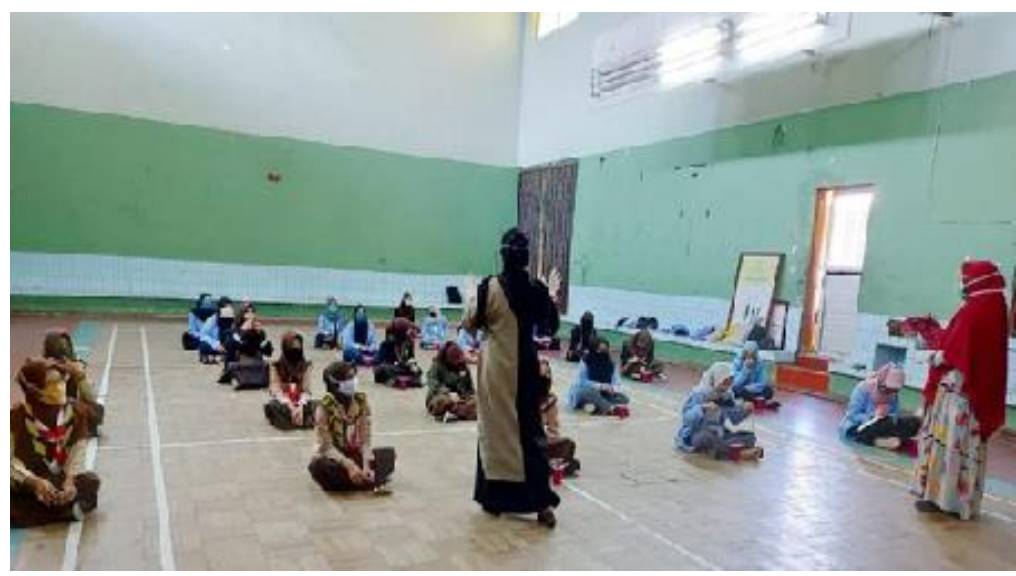

Gambar 5.Gambar pendidikan kesehatan oleh Tim

Dampak kegiatan pengabdian ini terdapat perubahan pengetahuan remaja sebelum dan sesudah pendidikan kesehatan. Pengetahuan remaja setelah dilakukan pengabdian masyarakat menjadi lebih paham tentang efektivitas kacang hijau dan kacang kedelai. Yang lebih efektif dalam meningkatkan kadar hemoglobin dan saturasi oksigen adalah kacang hijau.

\section{SIMPULAN}

Setelah dilakukan kegiatan pengabdian masyarakat berupa pemberian pendidikan kesehatanpada remaja diperoleh Kesimpulan pengabdian masyarakat yang telah dilakukan Terdapatpengaruh pada pengetahuan tentang efektivitas kacang hijau dan kacang kedelai dalam meningkatkan kadar hemoglobin dan saturasi oksigen dalam darah sabelum dan sesudah intervensi pendidikan kesehatan. Remaja menjadi tahu bagaimana pencegahan anemi, salah satunya dengan mengkonsumsi makanan berupa olahan kacang hijau dan kacang kedelai. Dan kacang hijau lebih dapat meningkatkan kadar hemoglobin 
dan saturasi oksigen dalam darah daripada kacang kedelai.

\section{DAFTAR PUSTAKA}

Arisman. 2011. Diabetes Mellitus: Dalam Buku Ajar Ilmu Gizi Obesitas dan Diabetes Mellitus dan Dislipidemia. Jakarta: EGC.

Astawan, M. 2009. Sehat dengan hidangan kacang dan biji-bijian. Swadaya: Depok.

Bappenas, BPS. 2013. Proyeksi Penduduk Indonesia 2015. Tersedia di: http://www.bappenas.go.id/ [diakses tanggal 2 April 2020]

Depkes RI. 2013. Pedoman penanggulangan Anemia Gizi di Indonesia. Jakarta. Direktorat Bina Gizi Masyarakat.

Fatimah, H. 2011. Pola Konsumsi dan Kadar Hemoglobin pada Ibu Hamil di Kabupaten Maros, Sulawesi Selatan.

Simanungkalit, S., \& Simarmata, O. (2019). Pengetahuan dan Perilaku Konsumsi Remaja Putri yang Berhubungan dengan Status Anemia. Buletin Penelitian Kesehatan, 47(3), 175-182. https://doi.org/10.22435/bpk.v47i3.1269

Suryani, S., I. (2019). Effectiveness of Green Beans and Soybeans in Increasing Hemoglobin and Oxygen Saturation Levels in Adolescent. Advances in Health Sciences Research, 2nd Bakti Tunas Husada-Health Science International Conference (BTH-HSIC 2019) volume 26

Yanuarti, F. 2014. Efek Suplemen besi, Vitamin C, dan peyuluhan Gizi terhadap Perubahan Kadar Hemoglobin Remaja Putri di Akademik Kebidanan Dharma husada Bondowoso. 